\section{Sociedade civil e espaços públicos no Brasil: um ba- lanço necessário}

Evelina DAGNINO (org.). Sociedade civil e espaços públicos no Brasil. São Paulo, Paz e Terra/Unicamp, 2002. 364 páginas.

\section{Cibele Saliba Rizek}

Como pensar os anos de 1990 no Brasil? Quais são seus temas centrais, seus desafios e suas dificuldades? Que embates conceituais se colocam a partir dessas reflexões? Quais categorias e quais objetos de investigação permitem a percepção das novidades e dificuldades? Essas são algumas das questões que o livro organizado por Evelina Dagnino coloca em discussão no âmbito das ciências sociais. Há, em sua organização, uma seleção e uma composição temática que permitem ao leitor percorrer o caminho proposto, repleto de questionamentos que se articulam por uma pergunta mais geral: quais são a natureza e os dilemas da democratização brasileira? Em outros termos, qual o resultado das novas relações entre sociedade civil e Estado no Brasil? A autora discute, assim, como os avanços no processo de democratização se articulam às velhas questões que marcaram historicamente as relações entre sociedade e política na cena brasileira.

O que primeiro chama a atenção é a diversidade temática que percorre os relatos e as análises de cada capítulo: orçamentos participativos e suas peculiaridades locais; conselhos gestores de políticas públicas; atuação das organizações nãogovernamentais; fóruns temáticos - em especial o Fórum de Reforma Urbana; MST em suas relações com o Estado nos programas de alfabetização do Paraná; Conselho Cearense de Direitos da Mulher; e, finalmente, semelhanças e especificidades entre os países do Cone Sul e o México, em seus desdobramentos recentes. A diversidade temática é parte constitutiva da reflexão, o que distancia o livro das montagens, cujo único mérito é o de abrigar objetos de pesquisa de articulação duvidosa. Em Sociedade civil e espaços públicos no Brasil, eles aparecem em constelação, o que permite que um conjunto de questões ganhe corpo em toda a sua complexidade.

É interessante notar que algumas das experiências que compõem os relatos e as análises são locais, enquanto outras - como o Fórum Nacional de Reforma Urbana, dizem respeito ao espectro nacional. Um mesmo artigo, por exemplo, constrói-se a partir de uma diversidade tipológica de experiências que problematiza a forma e a natureza das relações entre ONGs e Estado. Esse desenho bem-sucedido resulta da maneira cuidadosa com que as questões, que articulam essa multiplicidade de fenômenos, são tratadas, e isso é também conseqüência de um trabalho comum realizado durante a pesquisa Civil Society and Governance, financiada pela Fundação Ford, e ancorada, no caso brasileiro, em temas voltados para a qualidade e a natureza dos espaços públicos criados na década de 1990. Assim, a multiplicidade de escalas e questões faz parte do objeto mesmo de reflexão, tal como a organizadora comenta na Introdução e em um artigo que, ao fazer um balanço dos temas analisados, legitima a articulação do que é discutido, permitindo que linhas nem sempre uniformes constituam a reflexão maior da obra.

Para além das contribuições que resultam dos diversos objetos empíricos, os problemas e as questões mais instigantes ganham forma e densidade entre e a partir dos artigos. Essa constelação adquire centralidade porque se inscreve, ao mesmo tempo, em uma reflexão clássica ${ }^{1}$ e em seus desdobramentos contemporâneos, ou seja, a obra, como um todo, procura repensar as difíceis relações entre o Estado e a sociedade civil no Brasil.

Apesar da dimensão crítica e dos dilemas apontados em cada âmbito de investigação, os anos de 1990 são, inicialmente, caracterizados como a revitalização da sociedade civil, o que, nas palavras de Dagnino, pode ser identificado "com o aumento do associativismo, a emergência de movimentos sociais organizados, a reorganização partidária etc." e a própria democratização do Estado. As novas relações decorrentes desses processos, posteriores às práticas de resistência à ditadura militar, são apresentadas como "uma postura de negociação" assentada na "possibili- 
dade de uma atuação conjunta, expressa paradigmaticamente na bandeira da 'participação da sociedade civil' [...]". A grande novidade da década de 1990 residiria "na possibilidade de uma atuação conjunta, de 'encontros' entre o Estado e a sociedade civil". A avaliação dos resultados é conseqüência do panorama traçado pela pesquisa e pela pluralidade das contribuições temáticas. A diversidade e a complexidade de embates, confluências e disputas em torno do que se entende por democratização estão no centro das preocupações que percorrem todo o livro. Vislumbramse, assim, a possibilidade, a forma e o sentido da democratização brasileira.

Há no livro uma espécie de aposta nas possibilidades positivas da sociedade brasileira, presente, sobretudo, na Apresentação e em alguns exemplos mais "virtuosos", como os orçamentos participativos, mas isso não obscurece a dimensão crítica e a discussão acerca das problemáticas que, nos textos, ganham corpo quando se analisa as dificuldades e a diversidade de cada momento. Pela observação dos casos, por sua novidade, na medida do desafio que representam para as formas mais cristalizadas de se pensar a dinâmica política brasileira, o panorama de questões que surge em cada texto aponta para um conjunto de dimensões conceituais, ao contrário de generalizações ou modelos teóricos fechados e unívocos que conferem apenas uma possibilidade de análise aos elementos detectados nas cenas, nas relações de força, entre os atores do processo cada vez mais intenso de associativismo civil.

Marcado por uma mudança de tom, o texto que procura fazer um balanço das questões discutidas oferece ao leitor um quadro dos limites e das possibilidades da construção democrática brasileira. Trata-se de um processo não linear, contraditório e fragmentado que, segundo a autora, elimina "qualquer possibilidade de conceber a sociedade civil como o demiurgo do aprofundamento democrático" (p. 279) Tampouco o Estado pode ser visto dessa maneira, já que sua estrutura permanece atada ao desenho autoritário "largamente intocado e resistente aos impulsos participativos". Assim também, os partidos políticos são caracterizados por relações circunscritas na estru- tura do favor, do clientelismo e do personalismo, como marcas da precariedade de sua função mediadora. O autoritarismo brasileiro, que envolve o campo das relações sociais e das representações culturais e simbólicas, constitutivas das visões excludentes da sociedade e da política, é um obstáculo crucial e, ao mesmo tempo, o grande objeto de confronto. Os campos de conflitos que o questionam e o desnaturalizam talvez sejam um dos principais resultados da democratização dos espaços públicos, que passaram a constituir novas arenas de encontro e de embates.

As descobertas de pesquisa sintetizadas por Dagnino oferecem ao leitor uma idéia dos processos que ganham forma a partir das possibilidades e das dificuldades da atuação conjunta entre uma sociedade hierárquica e excludente e um Estado, cujas práticas autoritárias resistem aos "impulsos participativos". Os espaços públicos criados pela tensão e pelo conflito caracterizam momentos e práticas que se diferenciam em sua eficácia democratizante conforme a maior ou menor proximidade entre os projetos políticos que permeiam as relações entre Estado e sociedade civil. Para além de toda naturalização e/ou redução do caráter dessa relação, a autora afirma a natureza histórica e, por conseqüência, política que lhe é constitutiva. Assim, desprendendo-se do uso restritivo das categorias clássicas, a mediação dos projetos políticos ganha peso explicativo, porque " a clivagem estrutural entre Estado e sociedade civil não é suficiente para entender as suas relações e deve ser combinada com outras clivagens que não necessariamente coincidem com ela, mas a atravessam" (p. 281). Esse fato é reafirmado quando se tem em vista a expansão para a esfera do Estado de alguns projetos democratizantes que nasceram na sociedade civil. Dando prosseguimento à sua analise, Dagnino afirma que avaliar

[...] o impacto da sociedade civil sobre o desempenho do Estado (governance) é uma tarefa que não pode se apoiar num entendimento abstrato dessas categorias como compartimentos separados, mas precisa contemplar aquilo que as articula e as separa, inclusive aquilo que une e opõe as diferentes forças que as integram, os conjuntos de interesses expressos em escolhas políticas: aquilo 
que está sendo aqui designado como projetos políticos (p. 282).

Ela esclarece, ainda, que usa o termo projeto político "num sentido próximo da visão gramiscinana, para designar os conjuntos de crenças, interesses, concepções de mundo, representações do que deve ser a vida em sociedade, que orientam a ação política dos diferentes sujeitos" (p. 282, n. 3).

A avaliação desses processos, a eficácia e os significados desses espaços de encontro são ainda discutidos a partir das formas, das concepções e da natureza da participação da sociedade civil e de seus conflitos com o Estado, isto é, pela possibilidade de uma partilha efetiva do poder. As diversas concepções, articuladas a projetos políticos, estão no centro dos conflitos pela formulação e controle social das políticas públicas por parte da sociedade civil e das várias formas de resistência que o Estado oferece a essas iniciativas. Desse modo, quando a partilha efetiva do poder está comprometida, o que não parece ser ocasional, restam aos atores, oriundos da sociedade civil funções consultivas, executoras e/ou legitimadoras das decisões tomadas no interior da estrutura estatal. Ou seja, a partilha do poder pode, de fato, estar limitada e restrita, sem que haja possibilidade de esses atores deliberarem sobre as políticas públicas de âmbito mais geral. Como conseqüência, observa-se também uma insularização dos espaços de encontro, que acabam por se configurar como "institucionalidades paralelas" à estrutura estatal.

Assim, a participação da sociedade civil enfrenta limitações que se originam nas estruturas estatais pouco comprometidas com os processos de democratização, na burocratização, na penúria de recursos, na ineficácia, na instabilidade dos projetos que pressupõem a parceria com o Estado e, ainda, na exigência de qualificação técnica $e$ política que deveria estar vinculada à manutenção da autonomia e da capacidade de representação efetiva. Ademais, vale lembrar que, no interior da própria sociedade civil, há confronto entre diferentes projetos políticos, concepções e interesses. As dificuldades de reconhecimento da pluralidade e da busca de interesses comuns para além das diferenças, isto é, a constituição mesma da idéia de interesse público, são, de acordo com Dagnino, o núcleo de "um aprendizado" difícil: o da construção hegemônica.

Os projetos ligados à atuação conjunta entre Estado e sociedade civil foram agrupados em três grupos: projetos compartilhados, complementaridades e parcerias. Os elementos que definem o primeiro grupo - sem dúvida aquele cuja autora, na Introdução, aposta nas possibilidades construtivas dessa relação, dando ao texto um tom mais otimista, como já foi dito - apontam ora para confluências positivas entre a sociedade civil e o Estado, ora para conflitos marcados pela explicitação dos interesses envolvidos nos projetos políticos. O segundo grupo é analisado e avaliado nas suas dimensões instrumentais e a partir do que Dagnino caracteriza como confluência perversa

[...] entre um projeto participatório, construído, a partir dos anos 80, ao redor da extensão da cidadania e do aprofundamento da democracia, e o projeto de um Estado mínimo que se isenta progressivamente do papel de garantidor dos direitos. A perversidade está colocada no fato de que, apontando para direções opostas e até antagônicas, ambos os projetos requerem uma sociedade civil ativa e propositiva. Essa confluência perversa faz com que a participação da sociedade civil se dê hoje em terreno minado, onde o que está em jogo é o avanço ou o recuo de cada um destes projetos. Esse é um dilema que está presente na grande maioria dos estudos de caso e centraliza o debate que tenta avaliar as experiências de atuação conjunta com o Estado [...] (p. 289).

Os processos que nascem dessas perversidades acabam por confluir para uma situação dramática que envolve, especialmente, parte das relações entre ONG's e Estado, sobretudo quando as ONG's, consideradas qualificadas e confiáveis, recusam o papel e o lugar que lhes são atribuídos pelo Estado. Isso se agrava diante da possibilidade concreta de ações que, embora muitas vezes fragmentárias e provisórias, poderiam de fato diminuir a desigualdade, melhorando as condições de vida de populações que são alvo de programas sociais conjuntos.

Quanto ao terceiro grupo, alguns elementos que caracterizam as relações de complementari- 
dade se fazem presentes, em especial quando as ONG's são detentoras de competências específicas que faltam ao Estado. Aqui, entretanto, as ONG's que construíram suas competências a partir da incorporação das demandas de movimentos organizados vêem nessas práticas um instrumento que pode "afetar a ação estatal na direção da expansão da cidadania". Tais parcerias transformam-se, então, em reais possibilidades de alterar as pautas da ação estatal. Curiosamente, mas não por acaso, o exemplo mais claro disso pode ser observado nos projetos de alfabetização e educação no interior do MST, movimento que, ao longo dos anos de 1990, manteve padrões importantes de mobilização e visibilidade públicas.

Em relação à questão da representatividade, mais uma vez combinam-se elementos rigorosamente clássicos - especialmente quando referidos aos casos dos orçamentos participativos de Porto Alegre e Belo Horizonte e do MST - com o que se pode identificar como um deslocamento que faz das ONG's a vOz de interesses difusos, em nome dos seus vínculos (reais ou presumidos) com setores sociais, como jovens, portadores de HIV, negros, mulheres, entre outros. Porque detêm um conhecimento específico, porque acumulam um conjunto de competências, tornam-se representantes, contudo, trata-se mais de uma coincidência de interesses do que um resultado de uma relação orgânica entre representantes e representados. Vozes e porta-vozes articulam-se em torno de uma noção de representatividade que ganha outros sentidos, mesmo que em alguns dos casos analisados, como o do Conselho Cearense dos Direitos da Mulher - CCDM, sejam partidos que assumem e mantêm sob seu controle a representação da sociedade civil. Aqui também é possível identificar conflitos entre significados que se abrigam em um mesmo referente, uma vez que esse

[...] deslocamento da noção de representatividade não é obviamente inocente nem em suas intenções nem em suas conseqüências políticas. Seu exemplo mais extremo é o Conselho da Comunidade Solidária, vinculado ao governo federal, onde a representação da sociedade civil se dá através de convites a indivíduos com alta "visibilidade" na sociedade [...]. Esse entendimento particular da no- ção de representatividade a reduz à visibilidade social, entendida, por sua vez, como o espaço ocupado nos vários tipos de mídia (p. 291).

Quando esse deslocamento diz respeito às formas de representação da sociedade civil pelas ONGs, que se investem e são investidas desse caráter pelo Estado e pelas agências internacionais que buscam parceiros confiáveis, isso pode significar a despolitização, na medida em que sociedade civil e Terceiro Setor acabam por se confundir. Essa "onguização" parece se afirmar como tendência mundial, de sérias implicações, quer porque se vincula ao "modelo neoliberal", respondendo aos ajustes estruturais propostos, quer porque esse processo implica tanto o abandono dos vínculos dessas organizações com os movimentos sociais quanto a fratura de sua autonomia. Isso faz com que as organizações, que, a princípio, deveriam representar a sociedade civil, passem, cada vez mais, a responder para o Estado e as agências financiadoras, o que reduz sobremaneira o espectro público de sua atuação. Para além desses elementos, por si só problemáticos e instigantes, apontase ainda a necessidade de articulação entre as organizações da sociedade civil, mediante a proliferação das redes e dos fóruns, para que sua eficácia em relação ao Estado possa se constituir de fato, "tanto nos processos concretos de negociação como na inclusão de questões específicas na constituição da agenda estatal" (p. 292).

Entre o Estado e os movimentos sociais, entre institucionalização e mobilização, quais as perdas e os ganhos envolvidos nas estratégias e práticas resultantes dessas relações? Quais delas se comprometem com a construção democrática? Essas questões perpassam os diversos casos relatados, embora a análise do MST e dos orçamentos participativos demonstre que a polarização das relações não é inevitável, pois à dimensão institucional são vinculados os processos de politização, organização e mobilização social. No caso das ONG's, a avaliação parece ser diferente. Há, evidentemente, vantagens na atuação conjunta com o Estado, ao lado dos riscos de cooptação, subordinação, perda de autonomia e tecnificação, especialmente para as ONG's cujos "projetos políticos vão além de sua própria sobrevivência". 
A problemática apresentada abrange ainda o formato institucional dos espaços e dos fóruns de interlocução, o que também se configura como objeto de disputa entre projetos mais ou menos comprometidos com a democratização, seus embates e correlações de força. Como aponta Dagnino, os mesmos mecanismos e formatos que permitem avanços podem ser burlados na dinâmica concreta de funcionamento desses espaços.

Uma última dimensão, talvez a mais problemática e tensa, diz respeito ao mapeamento das discussões relativas à avaliação tanto da participação da sociedade civil como de seus encontros e desencontros com o Estado. Ao mapear as críticas que partem das expectativas de maximização dessas esferas, a autora afirma que elas são uma das múltiplas arenas

[...] em que se trava a disputa hegemônica, numa guerra de posições onde ações pontuais, de menor escopo e significado mais imediato, podem vir a se acumular molecularmente na direção de minar a ordem social desigual e significar a expansão de um projeto hegemônico alternativo, se [...] o projeto for capaz de manter um vínculo orgânico em relação a essas ações pontuais, conferindo-lhes uma articulação e direção próprias (p. 300).

Dagnino apresenta, por fim, uma última questão que problematiza as implicações advindas do que se entende por participação da sociedade civil no processo de construção democrática. Ela discute se a participação, os fóruns e os atores envolvidos se articulam na perspectiva da politização dos espaços de encontro, entendida como processo que embaralha os lugares demarcados para que de novo possam se instituir. Ou se essa participação se transforma em ingrediente central de uma gestão bem-sucedida de necessidades, que afirma, para além do aprendizado cultural da democracia, as práticas seculares da dominação, agora encobertas pelos signos de uma nova forma de legitimação. Entre a gestão e a política, ganha corpo a coragem do empreendimento e a operação bem-sucedida que fazem deste quebra-cabeça um lugar de disputas intensas e sem trégua em torno da questão democrática no Brasil.

\section{NOTA}

1 A caracterização dessa questão como clássica no pensamento brasileiro deve-se ao fato de esse tema ter sido objeto de análise de autores como Sérgio Buarque de Holanda, Raimundo Faoro, Florestan Fernandes, entre outros, assim como de estar no centro dos embates relativos aos sentidos da democracia no Brasil.

CIBELE SALIBA RIZEK é pesquisadora do Centro de Estudos dos Direitos da Cidadania e docente do Depto. de Arquiterura da EESC/USP. 